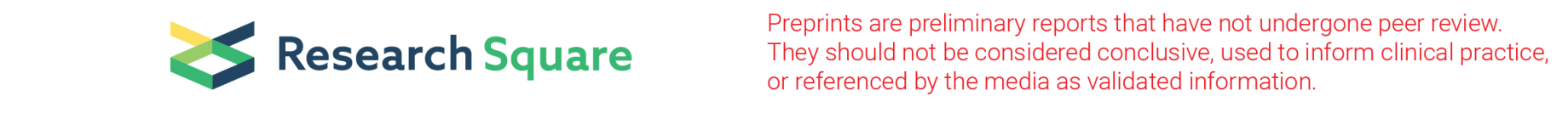

\title{
Using phytoplankton taxonomy diversity indices to assess trophic states in the biggest quake lake in China
}

\author{
yang Cai \\ Harbin Normal University \\ lin Qi \\ Harbin Normal University \\ chao MA \\ Harbin Normal University \\ xinxin Lu \\ Harbin Normal University \\ Yawen Fan ( $\nabla$ fanyaw_hrbnu@163.com ) \\ Harbin Normal University
}

\section{Research Article}

Keywords: Phytoplankton, quake lake, taxonomy diversity, trophic state index (TSI), Environmental characteristics

Posted Date: February 2nd, 2022

DOI: https://doi.org/10.21203/rs.3.rs-1162879/v1

License: @ (i) This work is licensed under a Creative Commons Attribution 4.0 International License. Read Full License 


\section{Abstract}

Water eutrophication is widely associated with the explosion of phytoplankton productivity and the overdominance of some harmful phytoplankton species. Phytoplankton diversity indices are useful tools for describing trophic states. The relationship between phytoplankton diversity indices and trophic states is a relevant approach to assess water quality, but this approach has rarely been used to evaluate water quality in large quake lakes. To test the usefulness of phytoplankton diversity indices in water quality assessment, we investigated the taxonomy diversity-trophic state index (TSI) relationships for lakes in the second-largest quake lake worldwide, (Jingpo Lake, in China). Our results showed that Cyanophyta and Bacillariophyta were abundant at most stations during the study period. The Bacillariophyta assemblage was closely associated with organic pollution. The Margalef index and Shannon-Weaver index were relevant tools for evaluating trophic changes during the study period. The Pielou index had a weak ability to describe nutrient changes. Our findings highlight that phytoplankton taxonomy diversity indices are relevant tools in water quality assessment, but a selection of the fit index is necessary.

\section{Introduction}

Phytoplankton are quantitatively vital primary producers in lake ecosystems (Amorim C. A. et al. 2019). In lakes, phytoplankton can comprise more than half of the total primary production (Bolgovics et al. 2019; Jacquemin et al. 2019). Due to their key role in lake food webs (Liu et al. 2020a), phytoplankton is a biological quality parameter that is widely used to monitor and assess freshwater ecosystems (Demir et al. 2014; Korneva \&Solovyeva 2021). Additionally, phytoplankton communities play an important role in bio-monitoring, particularly in indicating anthropogenic eutrophication (Liu et al. 2020b; Ward \&Van Oostende 2016). Phytoplankton diversity metrics are one of the most frequently used quantitative descriptors of water quality in a freshwater ecosystem (Behl et al. 2011; Marra et al. 2018). Biomass, sensitivity/tolerance, composition and bloom metrics are useful as ecological state indicators (Beisner \&Longhi 2013; Terseleer et al. 2014). Among these metrics, phytoplankton taxonomy diversity metrics have been widely used to assess water quality because they are simple to calculate and contain detailed ecological information (Nabout et al. 2007; Rodrigues et al. 2015; Schuster et al. 2015). A few advantages of phytoplankton biodiversity metrics in different aquatic systems (lotic or lentic ecosystems) are, for example, to describe lotic ecosystem properties, such as complexity, stability, and functioning (Schuster et al. 2015). In recent years, phytoplankton diversity metrics have become universal indices used for the assessment of biological quality in a lentic ecosystem (Nabout et al. 2007). Thus, testing the usefulness of phytoplankton taxonomy diversity metrics for water quality assessment is beneficial for biodiversity conservation.

Lake ecosystems experience various changes due to anthropogenic interference (Vitousek et al. 1997). The input of agrochemicals from agricultural activities, urbanisation, and tourism has a vital impact on lake ecosystems (Dudgeon et al. 2006). Urbanisation and anthropogenic discharge result in eutrophication in many inland lakes (Paerl \&Otten 2013). The loss of biodiversity and integrity is vital to the functioning of lakes (Strayer \&Dudgeon 2010). A significant measure of a healthy lake ecosystem is the state of the physical-chemical environment and diversity indices. However, most studies have proven that measuring physical and chemical water quality parameters do not accurately represent the status and disturbance events in lake systems over time (Rodrigues et al. 2015). Phytoplankton a diversity indices have proven to be the most successful in capturing such instant impacts caused by pollutants at very low concentrations (Nabout et al. 2007). An increase in the phytoplankton Shannon-Weaver index, such as the study in Lake Chaohu, may be a response to anthropogenic eutrophication (Jiang et al. 2014). Phytoplankton diversity patterns provide excellent information about anthropogenic impacts (Schuster et al. 2015). However, different results have been reported for eutrophication in different areas. It is worth noting that studies that focus on the correlation between phytoplankton diversity and trophic states in quake lakes remain poorly documented.

Heilongjiang Province is one of the most developed areas in northeastern China. The $90.3 \mathrm{~km} 2$ area of Jingpo Lake, China's largest quake lake, flows through the centre of this region. Jingpo Lake has experienced rapid industrialisation and urbanisation since the end of the 1970s and has become one of the largest hydroelectric power station regions and densely populated areas in northeastern China(Chen et al. 2015). Jingpo Lake is an important tourism and cultural area. Urbanisation, industrialisation, agriculture, and tourism have resulted in eutrophication and pollution in Jingpo Lake over the past decade. 
Previous studies have shown that Jingpo Lake is mesotrophic to eutrophic (Li et al. 2015). The phytoplankton community documented in Jingpo Lake indicates a low diversity and wide distribution of potentially harmful species (Lin et al. 2017; Song \&Yu 2009). However, none of these studies evaluated the relationship between phytoplankton a-diversity and trophic states in Jingpo Lake.

In this study, the Caelon's trophic state index (TSI) and four a-diversity indices (Shannon-Weaver index, Margalef index, Simpson index, and Pielou index) were measured in the rainy period (April) and dry period (August) during 2017-2018 in Jingpo Lake. Correlation analysis (CA) and spatial interpolation analysis (inverse distance weighting, IDW) were applied to understand the response of phytoplankton a-diversities to trophic states. We aimed (1) to evaluate the spatial and temporal variation in phytoplankton a-diversity indices in Jingpo Lake and (2) to test the usefulness of phytoplankton taxonomy diversity indices in trophic states assessment.

\section{Material And Method}

\section{Study area, Sample Collection and Laboratory Analyses}

Jingpo Lake is the largest mountain quake lake in China and the second-largest worldwide. The average depth of Jingpo Lake is $40 \mathrm{~m}$. The highest water level occurs from August to September (rainy season), and the lowest water level is recorded from March to April (dry season). Four sample collections were performed during the study period (April and August 2017, and April and August 2018). We collected water samples from 34 stations in Jingpo Lake (Fig. 1). Geographic coordinates were determined at each sampling station using a Garmin Etrex GPS. Water samples were collected using a $1 \mathrm{~L}$ water sampler. Water samples $(10 \mathrm{~L})$ were collected in plastic bottles preserved with $1 \%$ Lugol's solution and refrigerated under dark conditions until laboratory analysis (Jiang et al. 2014). At the same time as the phytoplankton sampling, $10 \mathrm{~L}$ samples for physical-chemical analyses were collected. All samples for physical-chemical analyses were immediately preserved in brown glass bottles at $4^{\circ} \mathrm{C}$. The YSI probe was used to assess the physical parameters, such as conductivity, dissolved oxygen, water temperature, and $\mathrm{pH}$. Total nitrogen (TN), total phosphorus (TP), chlorophyll-a (Chl-a), and chemical oxygen demand (COD) were determined according to Chinese national standards for water quality in the laboratory within $24 \mathrm{~h}$ (Jiang et al. 2014). The qualitative and quantitative analysis of phytoplankton metrics was performed following Rodrigues et al.. (Rodrigues et al. 2015).

\section{Taxonomy diversity indices}

Phytoplankton taxonomy diversity indices were evaluated using the Shannon-Weaver diversity, Margalef, and Pielou evenness indices.

Shannon-Weaver index:

$$
H^{\prime}=-\sum_{i=1}^{S} P i \times \ln P i
$$

Margalef index:

$$
H=(S-1) / \ln N
$$

Pielou evenness index:

$$
J=H^{\prime} / \ln S
$$

where $\mathrm{N}$ is the total number of all species in the sample, $\mathrm{S}$ is the total species in the sample, and $\mathrm{i}$ is the total number of individuals in species i.

\section{Statistical analysis}


In the current study, eight physicochemical parameters were considered for multivariate statistical analysis, including WT, DO, $\mathrm{EC}, \mathrm{pH}, \mathrm{Chl}-\mathrm{a}, \mathrm{TN}, \mathrm{TP}$, and COD. All eight factors and phytoplankton metrics were normalised using $\log 10(\mathrm{x} \pm 1)$ transformation.

Comprehensive TSI

A comprehensive TSI was used to determine the trophic status of Jingpo Lake. The equations for TSI are as follows:

$\operatorname{TSI}(\mathrm{TN})=10(5.453 \pm 1.694 \ln \mathrm{TN})$

$\operatorname{TSI}(\mathrm{TP})=10(9.436 \pm 1.642 \ln \mathrm{TP})$

$\mathrm{TSI}(\mathrm{Chl}-\mathrm{a})=10(2.5 \pm 1.086$ ln Chl-a $)$

$\operatorname{TSI}(C O D)=10(1.2 \pm 1.566 \ln C O D)$

$\operatorname{TSIM}\left(\sum\right)=[\mathrm{TSI}(\mathrm{TN}) \pm \mathrm{TSI}(\mathrm{TP}) \pm \mathrm{TSI}(\mathrm{COD}) \pm \mathrm{TSI}(\mathrm{Chl}-\mathrm{a})] / 4$

Evaluation standard: $0<\mathrm{TSIM} \leq 30$ oligotrophic, $30<\mathrm{TSIM} \leq 50$ mesotrophic, TSIM $>50$ eutrophic, $50<\mathrm{TSIM} \leq 60$ little eutrophic, $60<$ TSIM $\leq 70$ medium eutrophic, TSIM $>70$ high eutrophic.

\section{Results}

\section{Environmental characteristics and trophic states}

Five environmental parameters, water temperature, TN, TP, COD, and chlorophyll-a were significantly different $(p<0.05)$ across the two periods, whereas conductivity, $\mathrm{pH}$, and dissolved oxygen, were not significantly different $(\mathrm{p}>0.05 ;$ Table 1$)$. TN and TP were generally high during the dry season. These findings indicate that rainfall is a key component influencing environmental variables in temperate lakes. An analysis of the spatial and temporal variations in total TSI (the combination of the TSI for TP, TN, COD, and Chl-a) was performed (Fig. 2). The eutrophic state was recorded throughout the study period. TSI indicated that the trophic states of the study area ranged from mesotrophic to highly eutrophic (Fig. 2). The mean TSI in the dry season was $75 \pm 5$, similar to that in the dry season (mean TSI $=74 \pm 5)(p>0.01)$. There was a significant change in the total TSI between the rainy and dry seasons (Fig. 2; p $<0.01$ ).

Table 1

The temporal and spatial variation of environmental parameters during study period.

\begin{tabular}{|c|c|c|c|c|c|c|c|c|}
\hline & $\begin{array}{l}\text { SpCond } \\
(\mu \mathrm{s} / \mathrm{cm})\end{array}$ & $\begin{array}{l}\text { WT } \\
\left({ }^{\circ} \mathrm{C}\right)\end{array}$ & $\begin{array}{l}\text { DO } \\
\text { (mg/L) }\end{array}$ & $\mathrm{pH}$ & $\begin{array}{l}\text { TN } \\
(\mathrm{mg} / \mathrm{L})\end{array}$ & $\begin{array}{l}\text { TP } \\
(\mathrm{mg} / \mathrm{L})\end{array}$ & $\begin{array}{l}\text { COD } \\
(\mathrm{mg} / \mathrm{L})\end{array}$ & $\begin{array}{l}\text { Chl-a } \\
(\mu \mathrm{g} / \mathrm{L})\end{array}$ \\
\hline $\begin{array}{l}\text { Dry } \\
\text { season }\end{array}$ & $118.02 \pm 18.27$ & $17.86 \pm 1.54$ & $1.35 \pm 0.24$ & $9.00 \pm 0.73$ & $2.04 \pm 1.27$ & $0.15 \pm 0.15$ & $44.19 \pm 19.18$ & $8.68 \pm 6.81$ \\
\hline $\begin{array}{l}\text { Rainy } \\
\text { season }\end{array}$ & $107.25 \pm 31.52$ & $21.23 \pm 1.37$ & $1.03 \pm 0.43$ & $8.65 \pm 0.91$ & $3.26 \pm 1.37$ & $0.35 \pm 0.12$ & $21.98 \pm 6.89$ & $7.68 \pm 6.51$ \\
\hline 2017 & $109.85 \pm 33.15$ & $19.54 \pm 2.23$ & $1.00 \pm 0.38$ & $8.92 \pm 1.06$ & $2.12 \pm 1.02$ & $0.27 \pm 0.19$ & $31.97 \pm 22.23$ & $9.93 \pm 7.72$ \\
\hline 2018 & $115.42 \pm 16.48$ & $18.48 \pm 2.81$ & $1.37 \pm 0.28$ & $8.72 \pm 0.53$ & $3.55 \pm 1.34$ & $0.28 \pm 0.13$ & $31.20 \pm 16.32$ & $6.43 \pm 4.85$ \\
\hline \multicolumn{9}{|l|}{ T-Test } \\
\hline $\begin{array}{l}\text { Dry } \\
\text { season } \\
\times \\
\text { Rainy } \\
\text { season }\end{array}$ & $p>0.05$ & $p<0.05$ & $p>0.05$ & $p>0.05$ & $p<0.05$ & $p<0.05$ & $p<0.05$ & $p<0.05$ \\
\hline $\begin{array}{l}2017 \times \\
2018\end{array}$ & $p>0.05$ & $p>0.05$ & $p>0.05$ & $p>0.05$ & $p<0.05$ & $p>0.05$ & $p>0.05$ & $p<0.05$ \\
\hline
\end{tabular}




\section{Temporal-spatial variations of phytoplankton diversity indices}

A total of 147 species of phytoplankton belonging to six phyla and 75 genera were identified, including Chlorophyta (35.77\%), Bacillariophyta (34.15\%), Cyanophyta (13.10\%), Euglenophyta (12.20\%), and others (4.87\%). Phytoplankton abundance ranged from $4.00 \times 10^{4}$ ind./L to $716.34 \times 10^{4}$ ind./L during the study period. There was a significant variation in phytoplankton abundance in different hydrological periods $(p<0.05)$ (Table 2). Overall, Cyanophyta and Bacillariophyta were co-dominant in the study period, which contributed more than $80 \%$ total phytoplankton abundance (mean $=26.37 \times 10^{6}$ ind. $/ \mathrm{L}$ and $12.87 \times$ $10^{6}$ ind./L, respectively) (Table 2 ).

There was a significant change in the Margalef index between the dry and rainy seasons during the study period. The results of the t-test showed that the hydrological period difference was significant $(p<0.05$; Table 2). The Margalef index was $3.47 \pm 1.51$ in the dry season and $2.89 \pm 1.32$ in the rainy season (Fig. 3 and Table 2). The spatial and temporal distribution of the phytoplankton Shannon-Weaver index was similar to that of the Margalef index. The Shannon-Weaver index of the interconnected aquatic habitats was $1.79+0.50$ in the dry season and 1.91+0.57 in the rainy season. The Margalef and Shannon-Weaver index patterns revealed that the increased rainfall decreased the richness of the phytoplankton community. There was a significant difference in the Pielou index between the rainy and dry seasons ( $<<0.05 ;$ Fig. 5 and Table 2$)$. The Pielou index of the interconnected aquatic habitats was $0.59+0.17$ in the dry season and $0.72+0.12$ in the rainy season (Fig. 3). The Pielou index is an indicator of community species evenness. Our results showed that increased rainfall damages species evenness in Jingpo Lake.

Table 2

The temp oral and spatial variation of phytoplankton community structure and taxonomy diversity indices in Jingpo Lake between 2017-2018.

\begin{tabular}{|c|c|c|c|c|c|c|c|}
\hline & Dry season & $\begin{array}{l}\text { Rainy } \\
\text { season }\end{array}$ & 2017 & 2018 & $\begin{array}{l}\text { T- } \\
\text { test }\end{array}$ & $\begin{array}{l}\text { Dry } \\
\text { season x } \\
\text { Rainy } \\
\text { season }\end{array}$ & $2017 \times 2018$ \\
\hline $\begin{array}{l}\text { Abundance } \\
\left(\times 10^{4} \text { ind./L) }\right.\end{array}$ & $126.8 \pm 162.25$ & $37.14 \pm 77.37$ & $101.43 \pm 117.11$ & $139.47 \pm 77.1$ & & $P<0.05$ & $P>0.05$ \\
\hline $\begin{array}{l}\text { Bacillariophyta } \\
\left(\times 10^{4} \text { ind./L) }\right.\end{array}$ & $88.52 \pm 134.84$ & $24.92 \pm 73.11$ & $70.81 \pm 122.21$ & 97.37 & & $P<0.05$ & $P<0.05$ \\
\hline $\begin{array}{l}\text { Cyanophyta } \\
\left(\times 10^{4} \text { ind./L) }\right.\end{array}$ & $1.92 \pm 6.48$ & $2.36 \pm 6.64$ & $1.58 \pm 2.34$ & $2.17 \pm 12.1$ & & $P>0.05$ & $P>0.05$ \\
\hline $\begin{array}{l}\text { Chlorophyta }\left(\times 10^{4}\right. \\
\text { ind./L) }\end{array}$ & $9.99 \pm 32.87$ & $1.40 \pm 2.59$ & $7.99 \pm 2.01$ & $10.98 \pm 2.97$ & & $P>0.05$ & $P>0.05$ \\
\hline $\begin{array}{l}\text { Cryptophyta }\left(\times 10^{4}\right. \\
\text { ind./L) }\end{array}$ & $18.40 \pm 16.81$ & $5.95 \pm 6.35$ & $14.71 \pm 22.11$ & $20.23 \pm 11.10$ & & $P<0.05$ & $P<0.05$ \\
\hline $\begin{array}{l}\text { Euglenophyta } \\
\left(\times 10^{4} \text { ind./L) }\right.\end{array}$ & $7.74 \pm 23.24$ & $2.31 \pm 7.05$ & $6.19 \pm 12.1$ & $8.51 \pm 4.20$ & & $P<0.05$ & $P>0.05$ \\
\hline $\begin{array}{l}\text { other } \\
\left(\times 10^{4} \text { ind./L) }\right.\end{array}$ & $0.17 \pm 0.24$ & $0.21 \pm 0.23$ & $0.13 \pm 0.33$ & $0.18 \pm 0.11$ & & $P>0.05$ & $P>0.05$ \\
\hline Margalef & $3.47 \pm 1.51$ & $2.89 \pm 1.32$ & $2.73 \pm 1.44$ & $3.57 \pm 1.14$ & & $P<0.05$ & $P>0.05$ \\
\hline Shannon weaver & $1.79 \pm 0.50$ & $1.91 \pm 0.57$ & $1.77 \pm 0.55$ & $1.93 \pm 0.66$ & & $P>0.05$ & $P>0.05$ \\
\hline Pielou & $0.59 \pm 0.17$ & $0.72 \pm 0.12$ & $0.68 \pm 0.16$ & $0.62 \pm 0.18$ & & $P<0.05$ & $P>0.05$ \\
\hline
\end{tabular}


Table 3

The correlation coefficients of diversity indices in Jingpo Lake during the study periods. * indicates $p<0.05$ (two-tailed), ** indicates $\mathrm{p}<0.01$ (two-tailed).

\begin{tabular}{|c|c|c|c|c|c|}
\hline & & $\begin{array}{l}\text { Shannon-weaver } \\
\text { Dry-season }\end{array}$ & $\begin{array}{l}\text { Margalef Dry- } \\
\text { season }\end{array}$ & $\begin{array}{l}\text { Pielou Dry- } \\
\text { season }\end{array}$ & $\begin{array}{l}\text { Shannon weaver } \\
\text { Rainy-season }\end{array}$ \\
\hline \multirow{2}{*}{$\begin{array}{l}\text { Shannon-weaver Dry- } \\
\text { season }\end{array}$} & Correlation & 1 & $0.631^{\star \star}$ & $0.900^{\star \star}$ & -0.181 \\
\hline & Sig. & & 0 & 0 & 0.140 \\
\hline \multirow[t]{2}{*}{ Margalef Dry-season } & Correlation & $0.631^{* \star}$ & 1 & $0.278^{*}$ & 0.151 \\
\hline & Sig. & 0 & & 0.021 & 0.218 \\
\hline \multirow[t]{2}{*}{ Pielou Dry-season } & Correlation & $0.900^{\star \star}$ & $0.278^{*}$ & 1 & $-0.281^{*}$ \\
\hline & Sig. & 0 & 0.021 & & 0.020 \\
\hline \multirow{2}{*}{$\begin{array}{l}\text { Shannon weaver } \\
\text { Rainy-season }\end{array}$} & Correlation & -0.181 & 0.151 & $-0.281^{*}$ & 1 \\
\hline & Sig. & 0.140 & 0.218 & 0.020 & \\
\hline \multirow[t]{2}{*}{ Margalef Rainy-season } & Correlation & $-0.244^{\star}$ & 0.087 & $-0.309^{*}$ & $0.905^{\star \star}$ \\
\hline & Sig. & 0.045 & 0.479 & 0.010 & 0 \\
\hline \multirow[t]{2}{*}{ Pielou Rainy-season } & Correlation & 0.052 & $0.242^{*}$ & -0.066 & $0.417^{\star \star}$ \\
\hline & Sig. & 0.673 & 0.047 & 0.593 & 0 \\
\hline
\end{tabular}

Table 4

The correlation coefficients of diversity indices and TSI (trophic state index) in Jingpo Lake during the study periods. * indicates $p<$ 0.05 (two-tailed), ** indicates $p<0.01$ (two-tailed).

\begin{tabular}{|c|c|c|c|}
\hline & Margalef & Shannon-weaver & Pielou \\
\hline \multicolumn{4}{|l|}{ All } \\
\hline Correlation with TSI & $-0.105^{*}$ & $-0.178^{*}$ & -0.134 \\
\hline Sig. & $p<0.05$ & $p<0.05$ & $p>0.05$ \\
\hline \multicolumn{4}{|l|}{ Dry season } \\
\hline Correlation with TSI & $-0.366^{* *}$ & $-0.355^{\star \star}$ & $-0.269^{*}$ \\
\hline Sig. & $p<0.01$ & $p<0.01$ & $p<0.05$ \\
\hline \multicolumn{4}{|l|}{ Rainy season } \\
\hline Correlation with TSI & $0.361^{\star \star}$ & $0.388^{\star \star}$ & 0.004 \\
\hline Sig. & $p<0.01$ & $p<0.01$ & $p>0.05$ \\
\hline
\end{tabular}

\section{Discussion}

Phytoplankton diversity indices can respond to contamination at very low levels when the pollutants are present in the water column (Arab et al. 2019; Zhang et al. 2016). Phytoplankton diversity indices reflect the present state and past trends of accurate information with respect to environmental behaviour since they record cumulative changes over time (Motwani et al. 2014). In particular, phytoplankton taxonomy diversity indices have also been applied as a tool for assessing the impacts of hydrological connectivity on phytoplankton community dynamics (Ding et al. 2021; Hai D. N. et al. 2016). In the present study, 
we hypothesised that the phytoplankton taxonomy diversity indices have the potential to provide a signal correlation with water quality between different hydrological periods in Jingpo Lake. We found that the Margalef index and Shannon-Weaver index were closely related to changes in trophic states. Our findings verified our hypothesis that the phytoplankton taxonomy diversity indices were a potential indicator of water quality; however, the choice of the appropriate index is necessary.

Previous studies have shown that primary productivity is positively correlated with nutrient concentrations in lentic ecosystems. In the present study, the nutrient index (TN and TP) showed a significant decreasing trend from the dry season to the rainy season (Table $1, p<0.05$ ). We found a decrease in phytoplankton abundance from the dry season (average 126.8 $\times 104$ ind./L) to the rainy season (average $37.14 \times 104$ ind./L). These results can be attributed to the rainfall during the rainy season. The natural disturbance from rainfall leads to a decrease in phytoplankton abundance, which has been widely recorded in the template and trophic lakes(Onyango et al. 2020; Rooney et al. 2018). Meng et al. (2017) noted that rainfall events are a key component that affects phytoplankton colonisation and reproduction (Meng et al. 2017). The decreased abundance from the dry season to the rainy season indicated that the phytoplankton matrices are relevant tools to indicate the natural disturbance in barrier lakes. The COD concentration during the dry season $(44.19 \mathrm{mg} / \mathrm{L})$ was significantly higher than that during the rainy season $(p<0.05)$. COD is used as a chemical indicator to evaluate the water quality in the National Environmental Quality Standards for Surface Water of China (GB 3838-2002). Furthermore, COD concentration has been widely considered as an indicator of organic pollution in rivers and lakes(Shi et al. 2015; Wang et al. 2007). Here, Bacillariophyta dominated the phytoplankton community. COD is a key factor that impacts the diatom assemblage, as shown in prior studies (Arab et al. 2019; Pandey et al. 2018). Increased COD concentrations have a positive effect on colonisation and reproduction (Pandey et al. 2018). In terms of ecophysiological content, COD promotes the hydration of carbon dioxide during photosynthesis. The COD concentration was very high during the study period. This result further highlights that diatom assemblage is a vital indicator of organic pollution.

In the present study, based on CA and the IDW spatial interpolation analysis approach, we found that phytoplankton taxonomy diversity patterns are closely related to environmental condition changes between the rainy and dry seasons. Previous studies have shown that nutrients in lakes are important factors for phytoplankton communities, as they directly influence the spatial distribution and community composition (Xiao et al. 2021). Recent studies have shown that extreme nutrient input from anthropogenic activities leads to eutrophication and harmful algal blooms in lake ecosystems (Huang et al. 2014). Based on TSI, we found that JPH (Jingpo Lake) presents a mesotrophic to eutrophic state. The Margalef index quantifies the diversity relating specific richness to the total number of individuals (Korneva 2010). The t-test showed that the Margalef index was significantly higher in the dry season, suggesting that relatively lower nutrient concentrations can promote richness and evenness in the phytoplankton community, which conforms to Yang et al. (Yang et al. 2016). This may explain the low Margalef index values in the current study. Therefore, a significant negative correlation between the Margalef index and TSI was recorded in the present study (Table 4). Rainfall is considered a key component that influences phytoplankton colonisation and reproduction in aquatic ecosystems (Cho I. H. et al. 2020). We found a significant positive correlation between the Margalef index and TSI during the rainy season. These results could be attributed to natural disturbance from rainfall during the study period. Disturbance from rainfall not only impacts the light capture of phytoplankton but also in the intake of biotic and abiotic materials, including nutrients, accelerating a decrease in phytoplankton diversity and evenness (Cho I. H. et al. 2020). All of these results showed that the Margalef index had a vital ability to describe the trophic state in barrier lakes, but in particular, natural disturbances such as rainfall could weaken its efficiency. The Shannon-Weaver index is based on information theory and assumes that individuals are sampled at random from an "indefinitely large" community, and that all species are represented in the sample. Similar to the Margalef index, the Shannon-Weaver index appeared to be negatively correlated with TSI, suggesting that it is a relevant tool to indicate the nutrient concentration. Based on the results of the Margalef index and Shannon-weaver index, we found that disturbance of rainfall events could accelerate organism and nutrient transport, which may be an important reason for phytoplankton community succession. Contrary to our expectations, there was a weak negative correlation between the Pielou index and TSI during the study period. Moreover, a high nutrient concentration provided an appropriate condition for colonisation of pioneer species (C-strategy defined by Reynold). In eutrophic lakes, phytoplankton communities are mostly characterised by simplex richness and are dominated by contender species.

Page $7 / 15$ 
The Pielou index was considered a signal to indicate the evenness of the community in the lake ecosystem. The Pielou index is advantageous in focusing on evenness, however, is limited by abundance information. We found that the Pielou index had a vital ability to trace nutrients during the dry season. In the current study, the significant negative correlation between the Pielou index and TSI supports this point. This finding demonstrated that the environmental filter during the dry season had a weak influence on the evenness. The environmental conditions in Jingpo Lake such as deep water and high trophic state created favourable conditions for the competition for pioneer species, which led to low evenness with low Pielou index values. However, a positive correlation between the Pielou index and TSI in the rainy season revealed a natural disturbance of phytoplankton community evenness in barrier lakes.

Our study provides evidence that the Margalef index and Shannon-Weaver index contribute to an important part of the water quality framework. Understanding the relationships between phytoplankton taxonomy diversity indices and trophic states still faces challenges in ecological research. However, it is essential to establish a taxonomy index database of barrier lakes on a larger spatial and temporal scale.

\section{Conclusion}

Phytoplankton community patterns were developed in this study from 2017 to 2018 . We found that phytoplankton matrices had a positive correlation with increased nutrients, while the diatom distribution pattern was a potential indicator of organic pollution in the barrier lake. All the results indicated that phytoplankton taxonomy indices based on the Margalef and Shannon-Weaver indices offer relevant ecological information on the phytoplankton community structure. The ability of the Pielou index to indicate water quality was influenced by natural disturbances.

\section{Declarations}

\section{Ethics approval and consent to participate}

Not applicable

\section{Consent for publication}

Not applicable

\section{Availability of data and materials}

All data generated or analysed during this study are included in this published article.

The datasets used and/or analysed during the current study are available from the corresponding author on reasonable request.

\section{Competing interests}

The authors declare that they have no competing interests.

\section{Funding}

This work received financial aid extended by National Natural Science Foundation of China (31870187, 31970213), Natural Science Foundation of Heilongjiang, China (LH2020C067, YQ2020C032), Scientific Research Foundation of Harbin Normal University (XKB201912) and Harbin Normal University Doctoral Innovation Fund Project (HSDBSCX2019-04).

\section{Authors' contributions}

Xinxin Lu was a major contributor in writing the manuscript. Yang Cai, Lin Qi, Chao Ma, and Yawen Fan analyzed the data and make figures. All authors read and approved the final manuscript. 


\section{Acknowledgements}

Not applicable

\section{References}

1. Amorim CA, Valenca CR, Moura-Falcao RH, Moura AdN (2019) Seasonal variations of morpho-functional phytoplankton groups influence the top-down control of a cladoceran in a tropical hypereutrophic lake. Aquat Ecol 53:453-464

2. Arab S, Hamil S, Rezzaz MA, Chaffai A, Arab A (2019) Seasonal variation of water quality and phytoplankton dynamics and diversity in the surface water of Boukourdane Lake, Algeria. Arab J Geosci 12

3. Behl S, Donval A, Stibor H (2011) The relative importance of species diversity and functional group diversity on carbon uptake in phytoplankton communities. Limnol Oceanogr 56:683-694

4. Beisner BE, Longhi ML (2013) Spatial overlap in lake phytoplankton: Relations with environmental factors and consequences for diversity. Limnol Oceanogr 58:1419-1430

5. Bolgovics A, B-Beres V, Varbiro G, Krasznai-K EA, Acs E, Kiss KT, Borics G (2019) Groups of small lakes maintain larger microalgal diversity than large ones. Sci Total Environ 678:162-172

6. Chen R, Shen J, Li CH, Zhang EL, Sun WW, Ji M (2015) Mid- to late-Holocene East Asian summer monsoon variability recorded in lacustrine sediments from Jingpo Lake, Northeastern China. Holocene 25:454-468

7. Cho IH, Kim HK, Lee MH, Kim YJ, Lee H, Kim BH (2020) The Effect of Monsoon Rainfall Patterns on Epilithic Diatom Communities in the Hantangang River, Korea. Water 12

8. Demir AN, Fakioglu O, Dural B (2014) Phytoplankton functional groups provide a quality assessment method by the Q assemblage index in Lake Mogan (Turkey). Turk J Bot 38:169-179

9. Ding Y, Pan B, Zhao G, Sun C, Han X, Li M (2021) Geo-climatic factors weaken the effectiveness of phytoplankton diversity as a water quality indicator in a large sediment-laden river.Sci Total Environ792

10. Dudgeon D, Arthington AH, Gessner MO, Kawabata Z-I, Knowler DJ, Leveque C, Naiman RJ, Prieur-Richard A-H, Soto D, Stiassny MLJ, Sullivan CA (2006) Freshwater biodiversity: importance, threats, status and conservation challenges. Biol Rev 81:163-182

11. Hai DN, Nguyen_Ngoc L, T. NC (2016) ENSO and anthropogenic impacts on phytoplankton diversity in tropical coastal waters. Prog Oceanogr 140:1-13

12. Huang C, Li Y, Yang H, Sun D, Yu Z, Zhang Z, Chen X, Xu L (2014) Detection of algal bloom and factors influencing its formation in Taihu Lake from 2000 to 2011 by MODIS. Environ Earth Sci 71:3705-3714

13. Jacquemin C, Bertrand C, Franquet E, Mounier S, Misson B, Oursel B, Cavalli L (2019) Effects of catchment area and nutrient deposition regime on phytoplankton functionality in alpine lakes. Sci Total Environ 674:114-127

14. Jiang YJ, He W, Liu WX, Qin N, Ouyang HL, Wang QM, Kong XZ, He QS, Yang C, Yang B, Xu FL (2014) The seasonal and spatial variations of phytoplankton community and their correlation with environmental factors in a large eutrophic Chinese lake (Lake Chaohu). Ecol Indic 40:58-67

15. Korneva LG (2010) Changes in phytoplankton diversity in the Volga Basin waterbodies. Inland Water Biol 3:322-328

16. Korneva LG, Solovyeva VV (2021) Dynamics of Morphofuncitonal Groups of Phytoplankton in the Rybinsk Resrevoir and Assessment of the Resevoir Water Quality by the Community Index. Water Resour 48:65-72

17. Li YL, Liao MN, Chen R, Shen J (2015) Diatom-based inference of variations in the strength of East Asian spring wind speeds since mid-Holocene. Palaeogeogr Palaeocl 418:65-74

18. Lin K, Wang X, Wang Y, Zhou J, Liu L, Zhu Y, Xia Y (2017) Composition and Influencing Factors of Algal Functional Groups in Jingpo Lake. Res Environ Sci 30:520-528

19. Liu B, Chen S, Liu H, Guan Y (2020a) Blue-green algae enhanced performance of diatom-based multimetric index on de fining lake condition under high level of human disturbance.Sci Total Environ730 
20. Liu L, Zhu Y, Li B, Chen X (2020b) Assessment of phytoplankton biological integrity in Jiangsu section of Yangtze River based on MBFG. Water Resour Prot 36:13-20

21. Marra RC, Algarte VM, Ludwig TAV, Padial AA (2018) Diatom diversity at multiple scales in urban reservoirs in Southern Brazil reveals the likely role of trophic state. Limnologica 70:49-57

22. Meng PJ, Tew KS, Hsieh HY, Chen CC (2017) Relationship between magnitude of phytoplankton blooms and rainfall in a hyper-eutrophic lagoon: A continuous monitoring approach. Mar Pollut Bull 124:897-902

23. Motwani G, Raman M, Matondkar P, Parab S, Pednekar S, Solanki H (2014) Comparison between phytoplankton biodiversity and various indices for winter monsoon and inter monsoon periods in north-eastern Arabian Sea. Indian J Mar Sci 43:1513-1518

24. Nabout JC, Nogueira IdS, de Oliveira LG, Morais RR (2007) Phytoplankton diversity (alpha, beta, and gamma) from the Araguaia River tropical floodplain lakes (central Brazil). Hydrobiologia 575:455-461

25. Onyango AO, Xu H, Lin Z (2020) Diurnal cycle of rainfall over Lake Victoria Basin during the long-rain season based on TRMM satellite estimate. Int J Climatol 40:4622-4637

26. Paerl HW, Otten TG (2013) Harmful Cyanobacterial Blooms: Causes, Consequences, and Controls. Microb Ecol 65:9951010

27. Pandey LK, Lavoie I, Morin S, Park J, Lyu J, Choi S, Lee H, Han T (2018) River water quality assessment based on a multidescriptor approach including chemistry, diatom assemblage structure, and non-taxonomical diatom metrics. Ecol Indic 84:140-151

28. Rodrigues LC, Simoes NR, Bovo-Scomparin VM, Jati S, Santana NF, Roberto MC, Train S (2015) Phytoplankton alpha diversity as an indicator of environmental changes in a neotropical floodplain. Ecol Indic 48:334-341

29. Rooney GG, van Lipzig N, Thiery W (2018) Estimating the effect of rainfall on the surface temperature of a tropical lake. Hydrol Earth Syst Sc 22:6357-6369

30. Schuster KF, Tremarin PI, de Souza-Franco GM (2015) Alpha and beta diversity of phytoplankton in two subtropical eutrophic streams in southern Brazil. Acta Bot Bras 29:597-607

31. Shi X, Sun Z, Liu G, Xu H (2015) Insights into community-based discrimination of water quality status using an annual pool of phytoplankton in mid-subtropical canal systems. Environ Sci Pollut R 22:1199-1206

32. Song C, Yu H (2009) Phytoplankton Diversity in Jingpo Lake and Water Quality Evaluation. J of North-East Forestry University $37: 40-42$

33. Strayer DL, Dudgeon D (2010) Freshwater biodiversity conservation: recent progress and future challenges. $\mathrm{J}$ of the North American Benthological Society 29:344-358

34. Terseleer N, Bruggeman J, Lancelot C, Gypens N (2014) Trait-based representation of diatom functional diversity in a plankton functional type model of the eutrophied southern North Sea. Limnol Oceanogr 59:1958-1972

35. Vitousek PM, Aber JD, Howarth RW, Likens GE, Matson PA, Schindler DW, Schlesinger WH, Tilman D (1997) Human alteration of the global nitrogen cycle: Sources and consequences. Ecol Appl 7:737-750

36. Wang XI Lu, YI H, Gz H, Jy W Ty (2007) Exploration of relationships between phytoplankton biomass and related environmental variables using multivariate statistic analysis in a eutrophic shallow lake: A 5-year study. J Environ Sci 19:920-927

37. Ward BB, Van Oostende N (2016) Phytoplankton assemblage during the North Atlantic spring bloom assessed from functional gene analysis. J Plankton Res 38:1135-1150

38. Xiao J, Wang B, Qiu XL, Yang M, Liu CQ (2021) Interaction between carbon cycling and phytoplankton community succession in hydropower reservoirs: Evidence from stable carbon isotope analysis.Sci Total Environ774

39. Yang B, Jiang YJ, He W, Liu WX, Kong XZ, Jorgensen SE, Xu FL (2016) The tempo-spatial variations of phytoplankton diversities and their correlation with trophic state levels in a large eutrophic Chinese lake. Ecol Indic 66:153-162

40. Zhang M, Yu Y, Yang Z, Kong F (2016) Deterministic diversity changes in freshwater phytoplankton in the Yunnan-Guizhou Plateau lakes in China. Ecol Indic 63:273-281

Page $10 / 15$ 


\section{Figures}

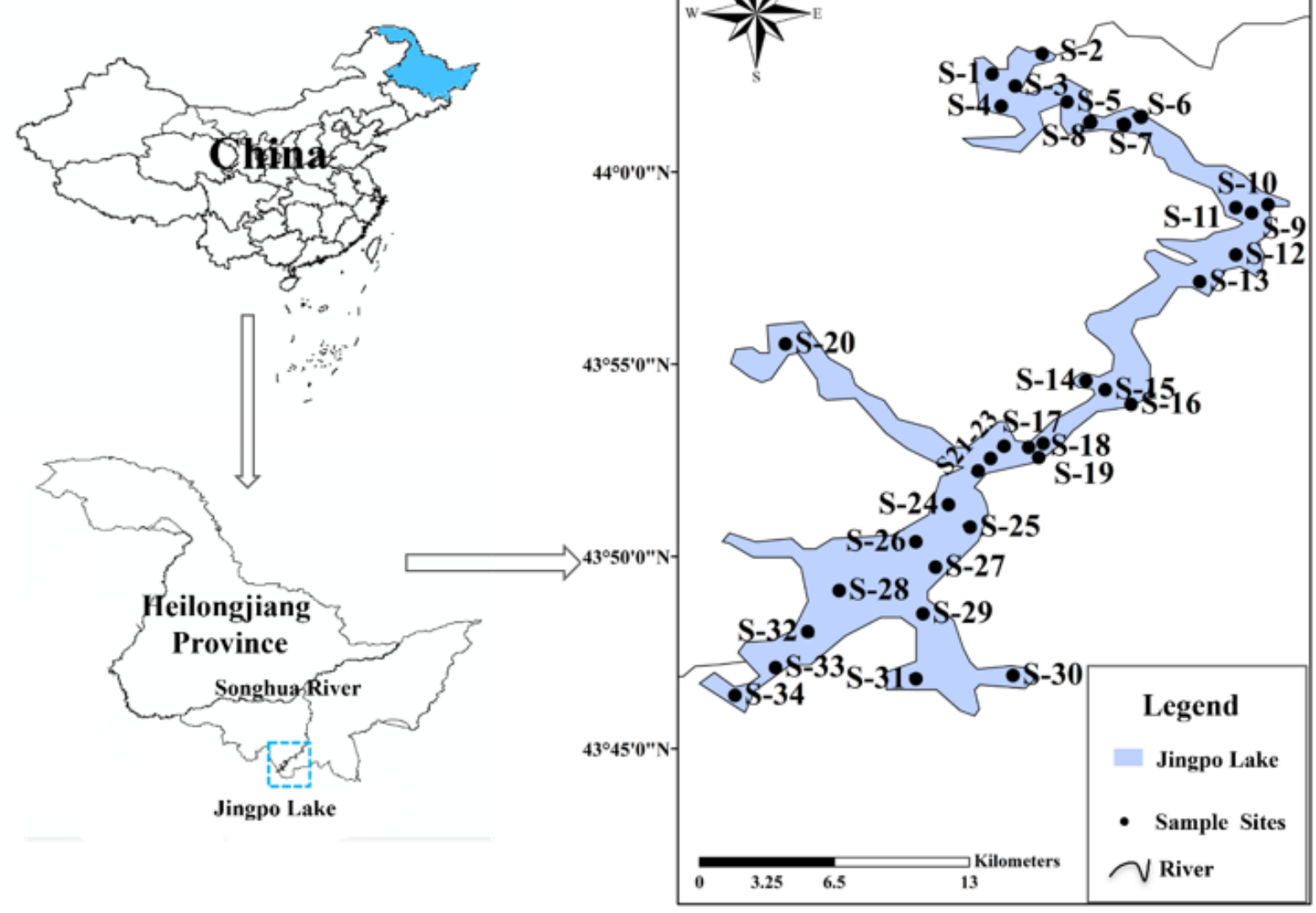

Figure 1

The location of sampling sites in the study area. 

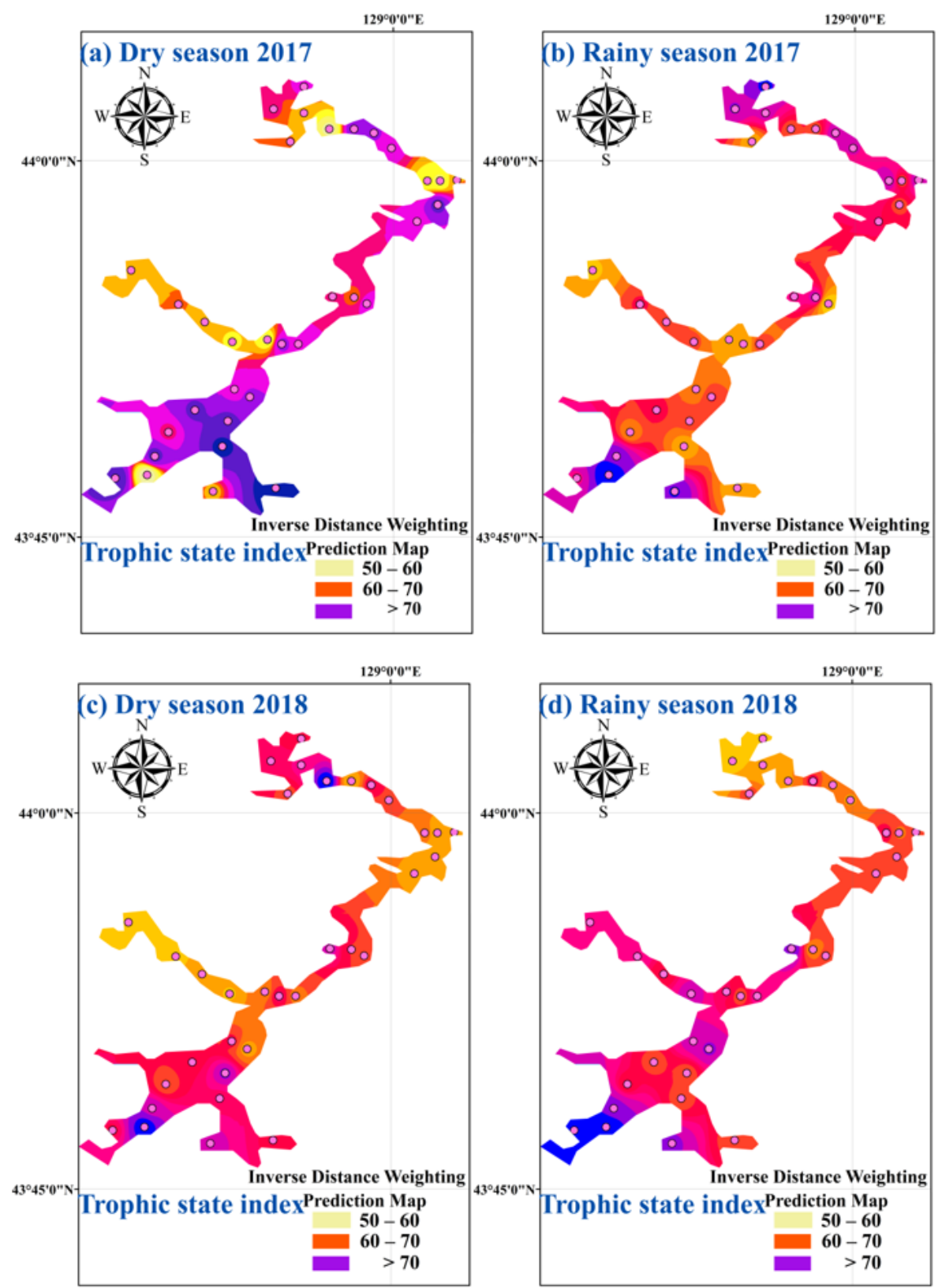

\section{Figure 2}

The spatial distribution of trophic state index (TSI) in the study period. (a) Dry season (April 2017); (b) Rainy season (August 2017); (c) Dry season (April 2018); (d) Rainy season (August 2018). The interpolation map was constructed using ArcGIS software and the inverse distance weighting method. 

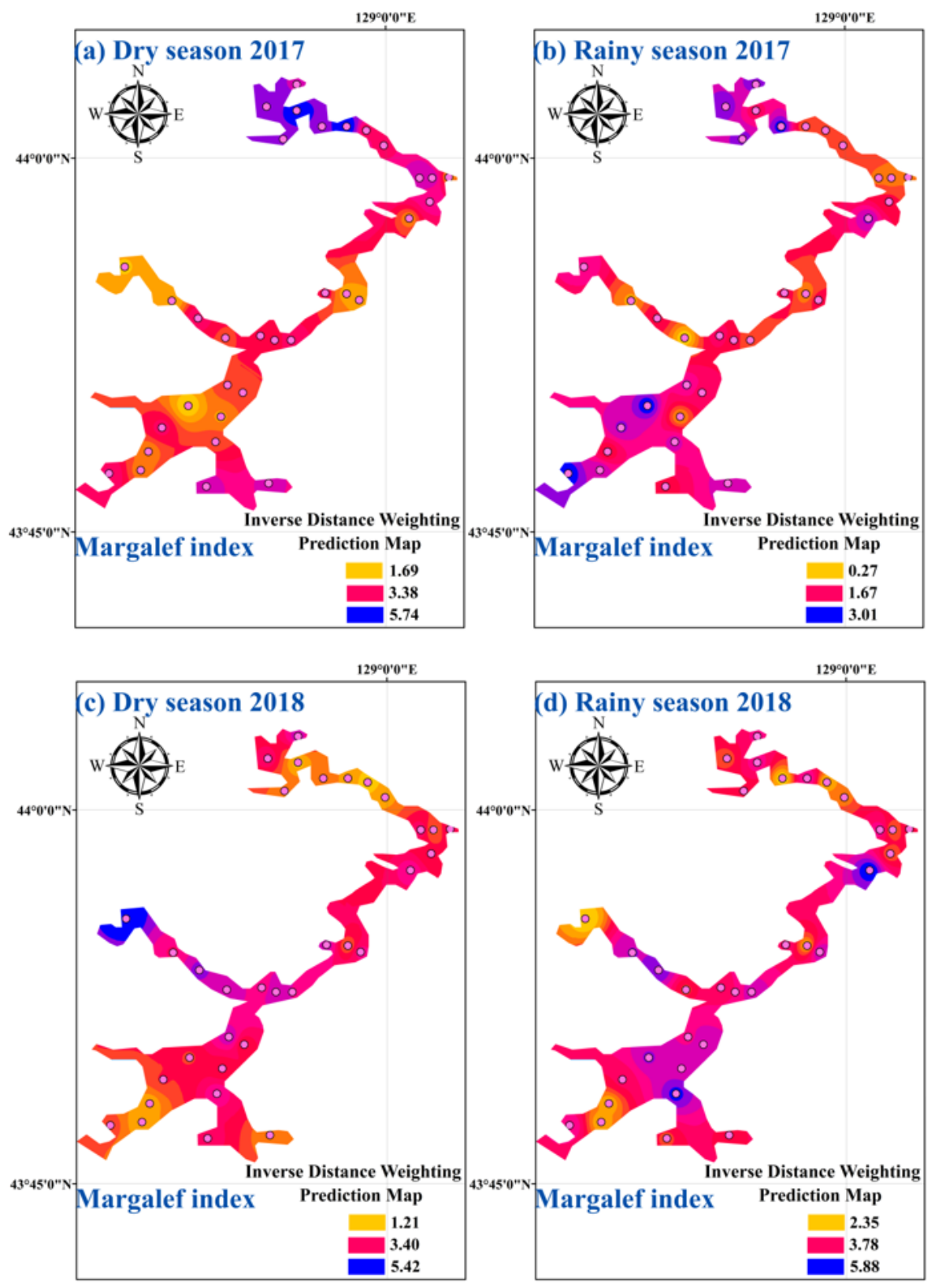

\section{Figure 3}

The spatial distribution of the Margalef index in the study period. (a) Dry season (April 2017); (b) Rainy season (August 2017); (c) Dry season (April 2018); (d) Rainy season (August 2018). The interpolation map was constructed using ArcGIS software using the inverse distance weighting method. 

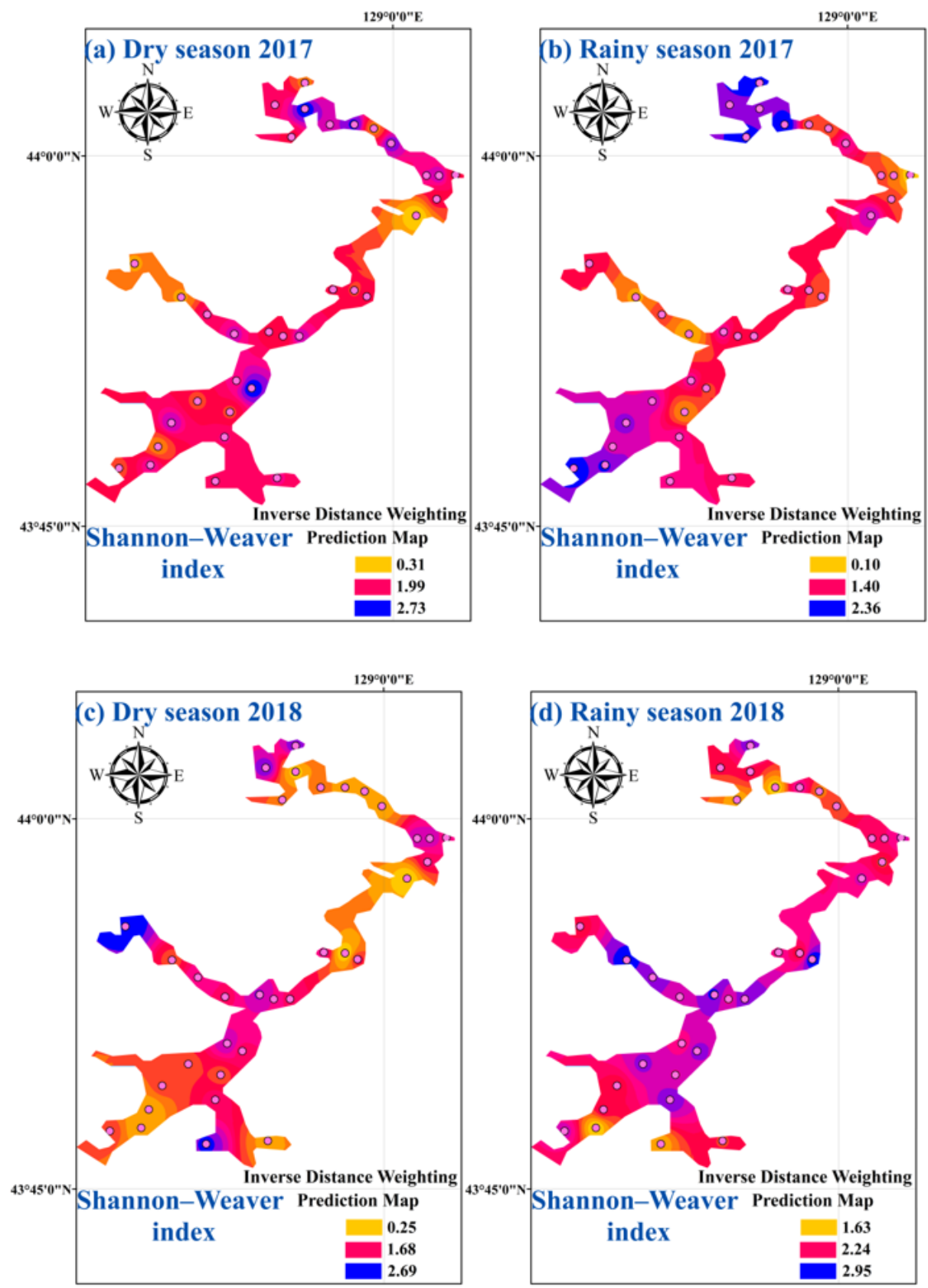

\section{Figure 4}

The spatial distribution of the Shannon-Weaver index in the study period. (a) Dry season (April 2017); (b) Rainy season (August 2017); (c) Dry season (April 2018); (d) Rainy season (August 2018). The interpolation map was constructed using ArcGIS software using the inverse distance weighting method. 

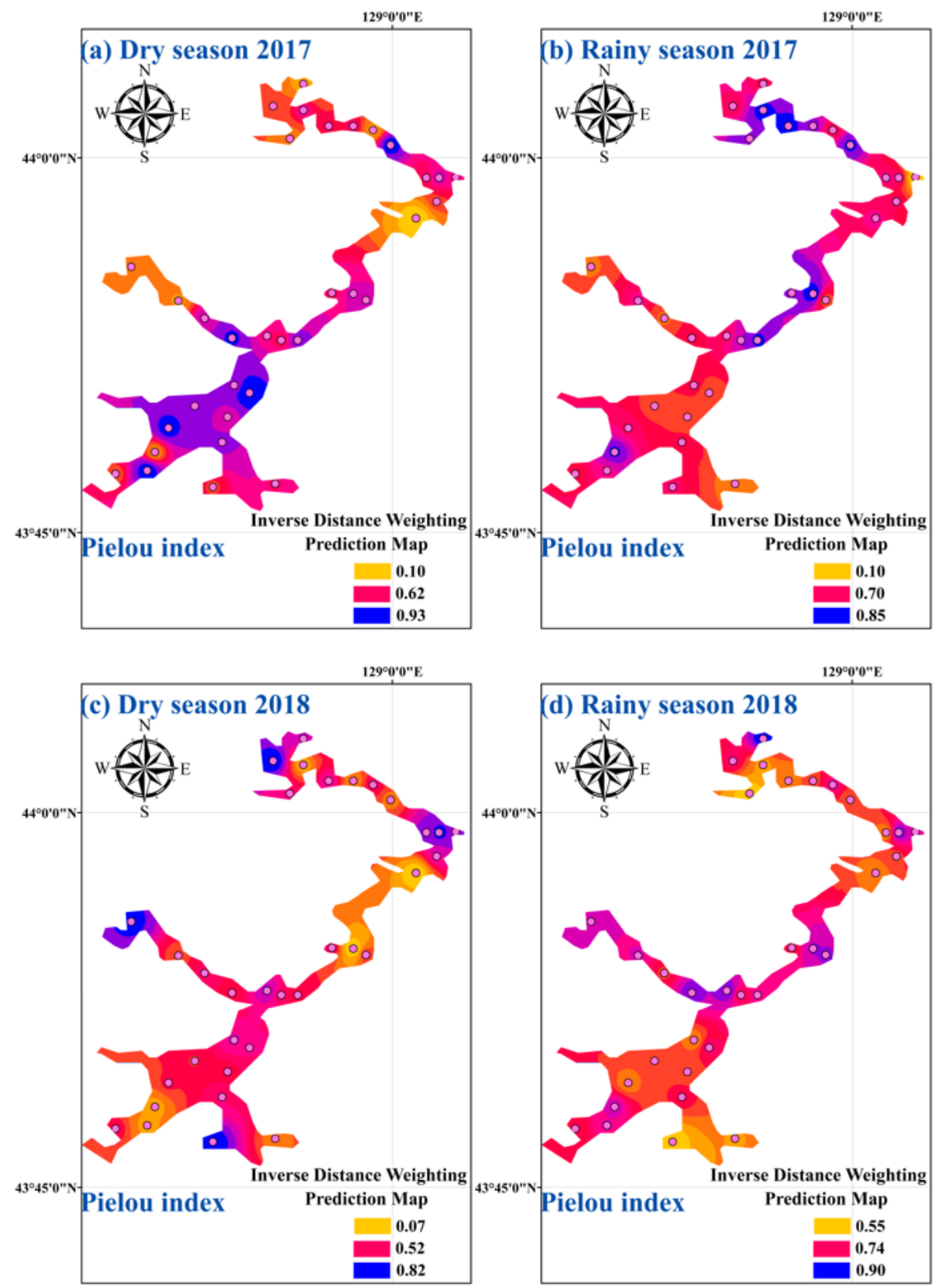

\section{Figure 5}

The spatial distribution of Pielou evenness index in the study period. (a) Dry season (April 2017); (b) Rainy season (August 2017); (c) Dry season (April 2018); (d) Rainy season (August 2018). The interpolation map was constructed using ArcGIS software using the inverse distance weighting method. 